DEMOGRAPHIC RESEARCH

VOLUME 32, ARTICLE 31, PAGES 859-872 PUBLISHED 7 MAY 2015

http://www.demographic-research.org/Volumes/Vol32/31/

DOI: 10.4054/DemRes.2015.32.31

Descriptive Finding

\title{
Post-divorce family trajectories of men and women in Flanders
}

Sofie Vanassche

Martine Corijn

Koen Matthijs

(c) 2015 Sofie Vanassche, Martine Corijn \& Koen Matthijs.

This open-access work is published under the terms of the Creative Commons Attribution NonCommercial License 2.0 Germany, which permits use, reproduction \& distribution in any medium for non-commercial purposes, provided the original author(s) and source are given credit.

See http://creativecommons.org/licenses/by-nc/2.0/de/ 


\section{Table of Contents}

$\begin{array}{lll}1 & \text { Introduction } & 860\end{array}$

$2 \quad$ Data and methods $\quad 861$

2.1 Data 861

$\begin{array}{lll}2.2 & \text { Method } & 861\end{array}$

$3 \quad$ Results 863

3.1 A typology of partner trajectories following divorce 863

3.2 A typology of parenthood trajectories following divorce 866

4 Conclusion $\quad 869$

$\begin{array}{ll}\text { References } & 871\end{array}$ 


\title{
Post-divorce family trajectories of men and women in Flanders
}

\author{
Sofie Vanassche ${ }^{1}$ \\ Martine Corijn ${ }^{2}$ \\ Koen Matthijs ${ }^{3}$
}

\begin{abstract}
BACKGROUND

Most studies investigating family life after a separation or divorce focus on single or competing events or transitions. Despite the growing popularity of the life-course perspective, few studies have given an overview of the sequence and timing of various post-divorce partner and parenthood trajectories.
\end{abstract}

\section{OBJECTIVE}

In this study we apply the technique of sequence analysis to describe the complete postdivorce partner and parenthood trajectory of divorced men and women in the first seven years following residential separation from their spouses.

\section{METHODS}

We use data from Divorce in Flanders, based upon a representative sample of first marriages drawn from the National Register. Our research sample consists of 1,530 men and 1,762 women who had been divorced for at least seven years at the time of interview. Ward's method is used as a clustering method.

\section{RESULTS}

A large proportion of divorced men and women remain single or outside a union, and make no partner or parenthood transition at all. However, we identified eight patterns of post-divorce partner trajectory and eight patterns of post-divorce parenthood trajectory. These trajectories differ from each other in the occurrence, the order, and the timing of specific partner and parenthood transitions.

\footnotetext{
${ }^{1} \mathrm{PhD}$, post-doctoral researcher FWO Flanders at the Centre for Sociological Research (Family and Population Studies), KU Leuven, Belgium. E-Mail: sofie.vanassche@soc.kuleuven.be (corresponding author).

${ }^{2} \mathrm{PhD}$, researcher at the Centre for Sociological Research (Family and Population Studies), KU Leuven, Belgium. E-Mail: martine.corijn@dar.vlaanderen.be.

${ }^{3} \mathrm{PhD}$, professor at the Centre for Sociological Research (Family and Population Studies), KU Leuven, Belgium. E-Mail: koen.matthijs@soc.kuleuven.be.
} 


\section{CONCLUSIONS}

Our results do not suggest complete de-standardization of the post-divorce family trajectories of men and women, but do suggest a substantial heterogeneity in postdivorce family life. This heterogeneity is often ignored or hidden by focusing on single events or family transitions.

\section{Introduction}

Events, transitions, and trajectories are important concepts in the sociology of the life course (Green 2010). Key questions arising from this perspective concern the timing and sequencing of events or transitions and the duration in between those events or transitions. In the present paper we explore the possibilities of sequence analysis to describe family trajectories of men and women following divorce in Flanders. Most studies that investigate family life after a separation or divorce are limited to single or competing events: second unions (e.g., Beaujouan 2012), remarriage versus new cohabitation (e.g., Wu and Schimmele 2005), or having a child within a new union (e.g. Jefferies, Berrington, and Diamond 2000). These studies give important insight into the determinants and timing of these events, but they do not provide an overview of the sequence and timing of various events and the temporal dynamics of family structures after a separation or divorce.

The initial aim of this paper was to apply sequence analysis to reconstruct one typology of family trajectory, including all partner and parenthood transitions following divorce. Sequence analysis was inspired by the idea of holistic trajectories, taking into account as many events as possible. But exploratory analyses revealed that the joint consideration of different types of partnership, the parenthood status of new partners, and any post-divorce childbearing resulted in a typology merely distinguishing clusters based upon event occurrence. Therefore the advantage of a holistic trajectory was counterbalanced by obtaining a cluster solution that ignored the ordering of statuses and timing of transitions. The main reason is the large number of possible statuses if the type of partnership is combined with the parenthood status of the partners and postdivorce childbearing. Thus we decided to work with two trajectories, each focusing on one specific characteristic of the family trajectory, partnership transitions or parenthood transitions. The first typology includes the timing, the stability, and the type of partner relationship (cohabitating or not, married or not). The second typology includes the timing of (unmarried or married) cohabitation with a partner with or without children, and (the timing of) a birth of a child within an (unmarried or married) cohabitation. 


\section{Data and methods}

\subsection{Data}

We use the data from the Divorce in Flanders (DiF) project (Mortelmans et al. 2011), in which a disproportional sample of one third of intact $(n=2502)$ and two thirds of dissolved $(n=6004)$ first marriages contracted between 1971 and 2008 was drawn from the Belgian National Register. These reference marriages were confined to marriages between partners of a different sex and with Belgian nationality, from birth on. Moreover, neither partner could be divorced more than once.

The two (ex-)partners from each reference marriage were invited to participate. At the end of the fieldwork (September 2010) 4,659 ex-partners from dissolved reference marriages were interviewed (response rate $=43 \%$ ), including 1,134 marriages of which both ex-partners participated in the study. By means of Computer Assisted Personal Interviewing, the complete partner and fertility trajectory was assessed. Restriction of the DiF-sample to men and women who had been separated for at least seven years at the time of interview resulted in a research sample of 1,530 men and 1,762 women.

\subsection{Method}

We use sequence analysis to construct two typologies of post-divorce family trajectory. All analyses and graphics are obtained using TraMineR (Gabadinho et al. 2011a). The trajectories are divided into time units and a specific status is assigned to each time unit. The goal is to identify clusters of similar trajectories in term of the type, duration, and sequence of the different statuses.

Both typologies are based on the transitions that occur following the date of residential separation from the spouse, and not the official divorce date. Several months or even years might pass between the residential separation and the legal divorce (Bastaits et al. 2011). Within that period, separated men and women may already have established new partnerships or new unions, or may even have produced children.

Because it is difficult to compare trajectories that are very different in length, we have chosen to limit the description of the post-divorce family trajectories to the first seven years following the residential separation. Prior research suggests that men and women who repartner or give birth after a union dissolution do so rather quickly (Buber and Prskawetz 2000; Pasteels, Corijn, and Mortelmans 2012). Both trajectories were divided into 84 time units of one month. By limiting the time frame to the first seven years following residential separation, we have information on the complete trajectory for men and women from more recent divorce cohorts. 
For the partner trajectory we distinguish four statuses: without partner (SINGLE), with a non-residential partner (LAT), in an unmarried cohabitation (LIV) and remarried (MAR). Only partnerships that lasted for at least three months were taken into account. As relationships may also be dissolved, we make a distinction according to the order of the partner $\left(1^{\text {st }}, 2^{\text {nd }}\right.$, etc. $)$. This enables us to distinguish consecutive relationships, also when there is no period of singlehood in between. We do not make this distinction for the remarried status, as people who divorced more than once were not included in the DiF-sample.

For the parenthood trajectory we distinguish five statuses: not in an (unmarried or married) union (SINGLE), union with partner without residential children of that partner and without common children with that partner (UNION), union with partner with residential children of that partner but without common children with that partner (UNION \& STEPCHILD), union with partner without residential children of that partner but with common child(ren) with that partner (UNION \& CHILD), and union with partner with residential children of that partner and with common child(ren) with that partner (UNION \& STEPCHILD \& CHILD).

For both trajectories, Ward's method was used as a clustering method to aggregate the individual sequences into a reduced number of meaningful groups based upon a socalled distance matrix (Gabadinho et al. 2011b). Distance matrices contain the distances between all pairs of sequences in the data set. It is important to note that the choice of a specific metric and cost-specification (and the resulting distance matrix) influences the results that are obtained.

We use the Average Silhouette Width or ASW value to measure the quality of the cluster solution (Studer 2012). This measure (range 0-1) gives a good indication of the coherence of the assignation of the sequences to the different clusters, or the degree to which the clusters are distinct from one another. An ASW value of more than 0.50 points towards a good cluster solution (Studer 2012).

The results that are presented for the partner trajectories are obtained using the Optimal Matching (OM) distance (Abbott and Forrest 1986). This distance is the minimal cost of transforming one sequence into the other by means of insertions, deletions, and substitutions, and the costs associated with these transformations (Gabadinho et al. 2011b). The indel costs were set at constant value 1 and the substitution costs were determined from the estimated transition rates with a minimum cost of 0 for the substitution of each state by itself, and a maximum value of less than 2; i.e., the value that we would get for a transition not observed in the data. The cluster solution with eight partner trajectories has an acceptable ASW value of 0.46. Additional trajectories do not substantially increase the ASW value and are less meaningful. Two alternative solutions were estimated using the Generalized Hamming Distance (HAM) and the Longest Common Subsequence (LCS). HAM generalizes the basic Hamming 
distance and accepts no insertions or deletions but only substitutions. All substitution costs were set to 1 (Gabadinho et al. 2011b). HAM is a position-wise measure and implies smaller distances in the case of similar timing. By contrast, LCS is based on the longest shared order of identical statuses between two sequences, without the condition of contiguous statuses (Elzinga 2007). Like OM, LCS focuses on similar state successions, without strict time alignment. Both alternative solutions were very similar to the solution obtained by OM with transition-rate specific substitution costs, but only the latter distinguished clearly the unstable post-separation partner trajectory.

The presented results for the parenthood trajectories are based upon the solution using the metric of the LCS. The cluster solution with eight parenthood trajectories has an ASW value of 0.64 , which indicates a clear distinction between the different clusters. The main difference from the two alternative solutions (HAM and OM with transitionrate specific substitution costs) is the clear distinction of a cluster combining postdivorce step-parenthood and childbearing.

As the two typologies in the present study are based upon different sequence metrics, our results demonstrate the importance of testing different metrics and cost specifications, as they influence the results that are obtained. For substantive reasons, the two respective distance metrics are more appropriate to capture relevant variation in the two types of trajectory.

\section{Results}

\subsection{A typology of partner trajectories following divorce}

Figure 1 presents the sequence index plots for the different clusters of partner trajectories, visualizing all individual sequences within each cluster. In these plots the individual sequences are rendered with horizontal bars depicting the statuses over every successive month. Table 1 presents the mean duration within the different statuses for each cluster, as well as the frequency distribution of the cluster solution for men and women separately. The distributions of men and women are overall quite similar (Chisquare $=13,0, \mathrm{df}=7, \mathrm{p}=0,07)$. 


\section{Figure 1: Sequence index plots of partner trajectories in the first seven years following divorce}

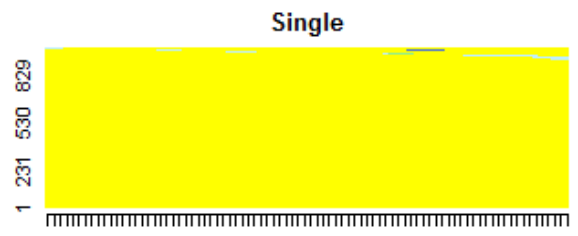

[1] [7] [14] [22] [30] [38] [46] [54] [62] [70] [78]

Fast unmarried cohabitation

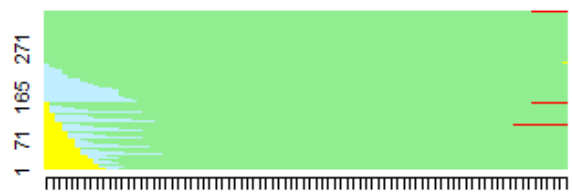

[1] [7] [14] [22] [30] [38] [46] [54] [62] [70] [78]

\section{LAT-relationship}

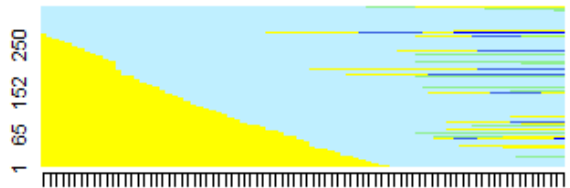

[1] [7] [14] [22] [30] [38] [46] [54] [62] [70] [78]

Fast remarriage

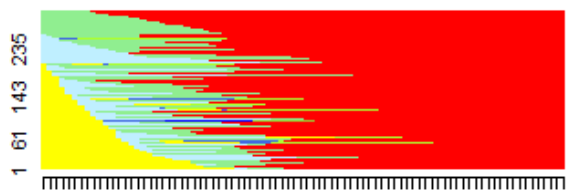

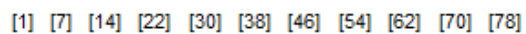

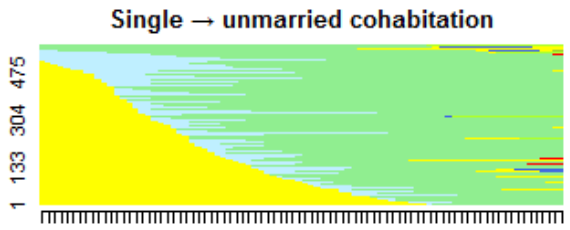

[1] [7] [14] [22] [30] [38] [46] [54] [62] [70] [78] Unmarried cohabitation $\rightarrow$ marriage

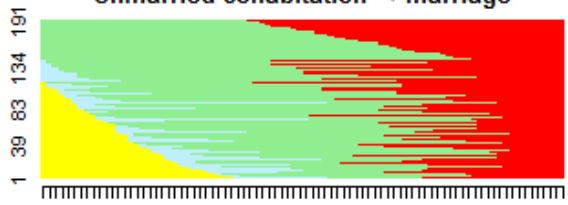

[1] [7] [14] [22] [30] [38] [46] [54] [62] [70] [78] Mainly single

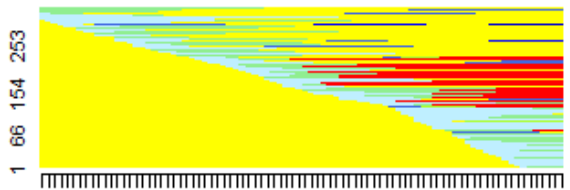

[1] [7] [14] [22] [30] [38] [46] [54] [62] [70] [78]

Multiple relationships

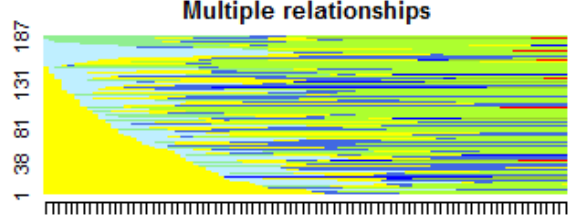

[1] [7] [14] [22] [30] [38] [46] [54] [62] [70] [78]

$$
\begin{aligned}
& \square \text { Single } \square \text { LAT2 } \square \text { LN3 } \square \text { LAT5 } \\
& \square \text { LAT1 } \square \text { LN2 } \square \text { LAT4 } \square \text { MAR } \\
& \square \text { LN1 } \square \text { LAT3 } \square \text { LNA }
\end{aligned}
$$

Note: SINGLE = Single, LAT1/LAT2/LAT3/LAT4 = LAT-relationship with, respectively, first, second, third, and fourth partner,

LIV1/LIV2/LIV3/LIV4 = Unmarried cohabitation with, respectively, first, second, third, and fourth partner, MAR = Remarried. 
Table 1: Mean duration in different statuses and frequency distribution of partner trajectories in the first seven years following divorce, by sex

\begin{tabular}{|c|c|c|c|c|c|c|c|c|c|c|c|c|c|c|c|}
\hline & \multicolumn{7}{|c|}{ Mean duration in different statuses } & \multicolumn{2}{|c|}{ Men } & \multicolumn{2}{|c|}{ Women } & \multicolumn{2}{|c|}{$\begin{array}{c}\text { Mean age at } \\
\text { separation }\end{array}$} & \multicolumn{2}{|c|}{$\begin{array}{c}\text { Mean ISCED } \\
\text { score }(0-8)\end{array}$} \\
\hline & SGL & LAT1 & LIV1 & LAT2 & LIV2 & MAR & ОтН & $\mathrm{n}$ & $\%$ & $\mathrm{~N}$ & $\%$ & Men & Women & Men & Women \\
\hline Single & 83 & 1 & 0 & 0 & 0 & 0 & 0 & 445 & 29 & 560 & 32 & 34.9 & 34.3 & 3.2 & 3.4 \\
\hline Mainly single & 56 & 11 & 7 & 2 & 1 & 5 & 2 & 162 & 11 & 170 & 10 & 33.7 & 31.7 & 3.5 & 3.8 \\
\hline LAT-relationship & 23 & 57 & 3 & 1 & 0 & 0 & 0 & 131 & 9 & 197 & 11 & 36.5 & 34.0 & 3.8 & 3.7 \\
\hline $\begin{array}{l}\text { Single } \rightarrow \text { unmarried } \\
\text { cohabitation }\end{array}$ & 24 & 10 & 48 & 1 & 1 & 0 & 0 & 286 & 18 & 289 & 16 & 33.1 & 30.8 & 3.5 & 3.5 \\
\hline $\begin{array}{l}\text { Fast unmarried } \\
\text { cohabitation }\end{array}$ & 2 & 4 & 78 & 0 & 0 & 0 & 0 & 176 & 12 & 179 & 10 & 34.0 & 31.1 & 3.5 & 3.5 \\
\hline $\begin{array}{l}\text { Unmarried } \\
\text { cohabitation } \rightarrow \\
\text { remarriage }\end{array}$ & 8 & 6 & 42 & 0 & 0 & 28 & 0 & 92 & 6 & 99 & 6 & 33.8 & 30.4 & 3.8 & 3.4 \\
\hline Fast remarriage & 7 & 9 & 12 & 1 & 2 & 53 & 0 & 138 & 9 & 170 & 10 & 33.8 & 29.8 & 3.6 & 3.6 \\
\hline Multiple relationships & 23 & 11 & 6 & 15 & 25 & 0 & 5 & 91 & 6 & 96 & 5 & 34.0 & 30.6 & 3.9 & 3.6 \\
\hline Total & 40 & 11 & 22 & 1 & 2 & 7 & 1 & 1521 & 100 & 1760 & 100 & 34.3 & 32.2 & 3.5 & 3.6 \\
\hline
\end{tabular}

Note: SGL = Single, LAT1/LAT2 = LAT-relationship with, respectively, first and second partner, LIV1/LIV2 = Unmarried cohabitation with, respectively, first and second partner, MAR = Remarried, OTH: LAT- or unmarried cohabitation with third, fourth, or fifth partner.

The first trajectory is that of men and women who remain Single during the first seven years following divorce. This is the largest cluster in size. There is also a smaller cluster, Mainly single, in which divorcees are single for approximately five of the seven years. The cluster LAT-relationship contains divorcees who started a new relationship without cohabiting or remarrying. On average, this group had a non-residential partner for 4.5 years. All other clusters contain divorcees who started a new union. The first group, Fast unmarried cohabitation, (almost) immediately starts cohabiting, and lives with that new partner for 6.5 years on average. By contrast, in the group Single $\rightarrow$ unmarried cohabitation, divorcees first live for approximately two years without a partner before starting to cohabit. Next, there are two clusters in which remarriage occurs, distinguished by the timing of the remarriage. In the cluster Unmarried cohabitation $\rightarrow$ remarriage, divorcees first live together unmarried for 3.5 years on average before getting married. The second group, Fast remarriage, remarries after about one year of unmarried cohabitation and is larger than the previous group. Finally, there is a small group of divorcees who cumulate consecutive partnerships in the seven years following divorce. This cluster is labeled Multiple relationships.

We explored in a descriptive way differences between the clusters in terms of the mean age at residential separation $(\mathrm{F}=16.0, \mathrm{df}=7, \mathrm{p}<.0001)$ and the educational level in 
terms of the ISCED 2011-score, range 0 to $8(\mathrm{~F}=3.2, \mathrm{df}=7, \mathrm{p}=0.0026)$. Men and women in the cluster LAT-relationship were on average older at the time of divorce and have a higher educational level compared to men and women in most other clusters. Men in the cluster Single are on average lower educated than those in other clusters, while women in this cluster are on average older than those in the other clusters.

\subsection{A typology of parenthood trajectories following divorce}

Next, we discuss the results for the parenthood trajectories of men and women following divorce. Figure 2 presents the sequence index plots for the different clusters. Table 2 reports the mean duration within the different statuses for each cluster and the frequency distribution of those trajectories for men and women separately.

The cluster No union contains divorcees who do not start a new union within the first seven years following divorce. The next three clusters contain divorcees who start a new union with a partner who does not have residential children from a previous union, and with whom they do not have a common child within that period. These three clusters are distinguished from one another by the duration of the singlehood period preceding the new union: Long-term no union $\rightarrow$ union (on average 5 years single), No union $\rightarrow$ union (on average 2 years single), and Fast union (on average 0.5 years single). The next two clusters contain divorcees who start a new union with a partner who brings in residential children. Within the cluster Fast union and stepchild, this happens on average within the first half year following the separation. Within the cluster No union $\rightarrow$ union and stepchild, men and women are on average single for three years after separation. Within the final two clusters, divorcees have a common child within their new union. In the cluster Union and child, the partner has no residential children from a previous relationship, in contrast with those in the cluster Union, stepchild, and child. In both clusters, men and women are single for 1.5 years on average before starting a new union. The (first) birth follows on average two years after the start of the new union. The proportion of divorcees that has a child with a partner who has residential children from a previous union is very small. 


\section{Figure 2: Sequence index plots for parenthood trajectories following divorce}
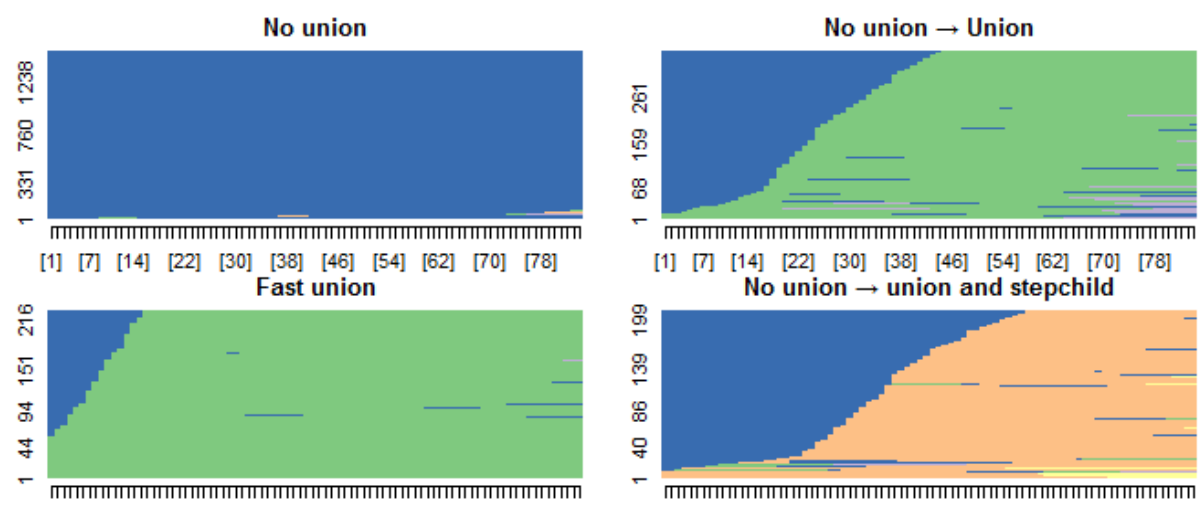

[1] [7] [14] [22] [30] [38] [46] [54] [62] [70] [78] Union and child

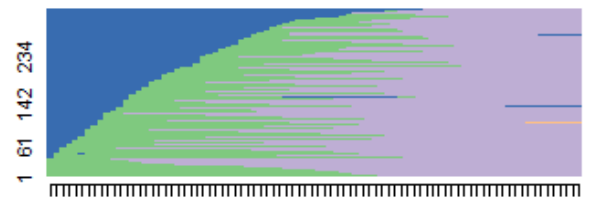

$[1]\left[\begin{array}{lllllllll}{[14]} & {[22]} & {[30]} & {[38]} & {[46]} & {[54]} & {[62]} & {[70]} & {[78]}\end{array}\right.$ Longterm no union $\rightarrow$ union

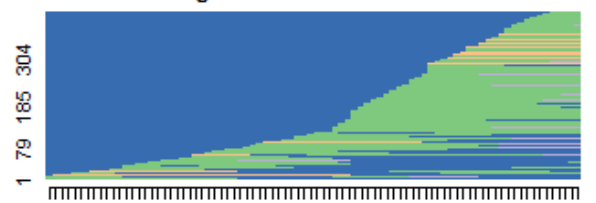

[1] [7] [14] [22] [30] [38] [46] [54] [62] [70] [78] Fast union and stepchild

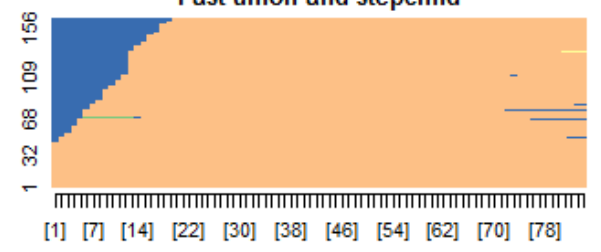

[1] [7] [14] [22] [30] [38] [46] [54] [62] [70] [78] Union, stepchild and child

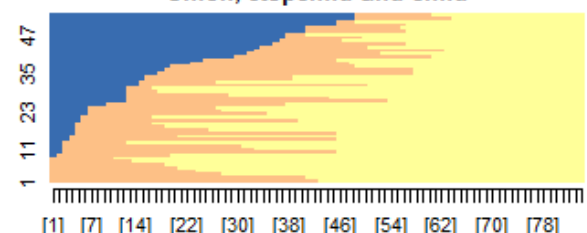

$\left[\begin{array}{lllllllllll}{[1]} & {[7]} & {[14]} & {[22]} & {[30]} & {[38]} & {[46]} & {[54]} & {[62]} & {[70]} & {[78]}\end{array}\right.$

Summarizing in terms of parenthood trajectories, the first four trajectories imply no change in parenthood status following separation. The fifth and sixth trajectory imply a transition to step-parenthood. Divorcees in the seventh trajectory experience the birth of at least one child within the new union. In the last trajectory the birth of a common child with the new partner is preceded by a transition to step-parenthood. 
Vanassche, Corijn \& Matthijs: Post-divorce family trajectories of men and women in Flanders

Table 2: Mean duration in different statuses and frequency distribution of parenthood trajectories in the first seven years following divorce, by sex

\begin{tabular}{|c|c|c|c|c|c|c|c|c|c|c|c|c|c|}
\hline & \multicolumn{5}{|c|}{ Mean duration } & \multicolumn{2}{|c|}{ Men } & \multicolumn{2}{|c|}{ Women } & \multicolumn{2}{|c|}{$\begin{array}{c}\text { Mean age at } \\
\text { separation }\end{array}$} & \multicolumn{2}{|c|}{$\begin{array}{l}\text { Mean ISCED } \\
\text { score }(0-8)\end{array}$} \\
\hline & Single & Union & $\begin{array}{l}\text { Union + } \\
\text { stepchild }\end{array}$ & $\begin{array}{l}\text { Union + } \\
\text { child }\end{array}$ & $\begin{array}{l}\text { Union + } \\
\text { stepchild } \\
\text { + child }\end{array}$ & $\mathrm{n}$ & $\%$ & $\mathrm{n}$ & $\%$ & Men & Women & Men & Women \\
\hline No union & 84 & 0 & 0 & 0 & 0 & 672 & 44 & 846 & 48 & 35.3 & 35.1 & 3.4 & 3.4 \\
\hline $\begin{array}{l}\text { Long-term no union } \\
\rightarrow \text { Union }\end{array}$ & 58 & 21 & 3 & 1 & 0 & 196 & 13 & 225 & 13 & 32.8 & 32.8 & 3.5 & 3.5 \\
\hline No union $\rightarrow$ union & 27 & 56 & 0 & 2 & 0 & 167 & 11 & 194 & 11 & 32.8 & 32.8 & 3.5 & 3.5 \\
\hline Fast union & 7 & 78 & 0 & 0 & 0 & 80 & 5 & 148 & 8 & 35.7 & 35.7 & 3.4 & 3.4 \\
\hline $\begin{array}{l}\text { No union } \rightarrow \text { union } \\
\text { and stepchild }\end{array}$ & 35 & 1 & 47 & 0 & 1 & 139 & 10 & 71 & 4 & 35.1 & 35.1 & 3.6 & 3.6 \\
\hline $\begin{array}{l}\text { Fast union and } \\
\text { stepchild }\end{array}$ & 7 & 0 & 77 & 0 & 0 & 96 & 6 & 68 & 4 & 36.3 & 36.0 & 3.5 & 3.5 \\
\hline Union and child & 18 & 22 & 0 & 44 & 0 & 134 & 9 & 190 & 11 & 31.9 & 31.9 & 3.8 & 3.8 \\
\hline $\begin{array}{l}\text { Union, stepchild, } \\
\text { and child }\end{array}$ & 16 & 0 & 0 & 22 & 46 & 34 & 2 & 19 & 1 & 29.7 & 29.7 & 3.2 & 3.2 \\
\hline Total & 54 & 17 & 8 & 5 & 1 & 1518 & 100 & 1761 & 100 & 34.3 & 32.2 & 3.5 & 3.6 \\
\hline
\end{tabular}

In contrast to the partner trajectories, there are clear differences in the male and female distribution of the trajectories (Chi-Square $=67.3, \mathrm{df}=7, \mathrm{p}<0.001$ ). There are twice as many men than women in the clusters No union $\rightarrow$ union and stepchild, Fast union and stepchild, and Union, stepchild, and child. Women more often have no new union within the first seven years following divorce, and if they do their partner has residential children less often.

As for the partner trajectories, we explored in a descriptive way differences between the clusters in terms of mean age at separation $(\mathrm{F}=37.2, \mathrm{df}=7, \mathrm{p}<.0001)$ and educational level in terms of the ISCED 2011-score $(\mathrm{F}=2.76, \mathrm{df}=7, \mathrm{p}=0.0074)$. The most pronounced finding is the lower age at separation and the lower educational level of both men and women in the cluster Union, stepchild, and child. Conversely, the mean educational level of men and women in the cluster Union and child is high. Men and women in the clusters No union, Fast union, and Fast union and stepchild are on average older than men and women in the other clusters. 


\section{Conclusion}

In this paper we described the post-divorce family trajectories of men and women in terms of repartnering, union formation and remarriage, childbearing, and the transition to step-parenthood in Flanders. By looking at these transitions as a sequence of events instead of single, independent events, we gain insight into the order and timing of the partner and parenthood trajectories following divorce.

A first general conclusion concerns the prevalence of specific family transitions following divorce. Almost one in three men and women remain single during the first seven years following the residential separation with their spouse. The majority of men and women, however, repartner quite fast. Most of them have a quite stable postdivorce family life, and experience no additional relationship dissolution. Although we might underestimate the proportion of unstable (post-divorce) family trajectories due to the exclusion of second divorces from the SiV-sample, this underestimation is quite limited as the large majority of second divorces take place after age 50 (Corijn 2013). Two other reasons why unstable post-divorce trajectories might be underestimated are that only relationships that lasted for at least three months were reported in the dataset and that divorcees with unstable trajectories may participate less in surveys.

The second general conclusion is that there are important variations in the family trajectories of divorced men and women in Flanders. The obtained typologies nicely illustrate the heterogeneity in terms of the nature and timing of post-divorce partnerships (cohabiting or not, married or not), the birth of children within these new unions, and the parenthood status of the new partner. Within both typologies, none of the trajectories involving at least one transition can be identified as 'the standard trajectory', illustrating the outcome of the de-standardization of post-divorce family life during the last decades (Shanahan 2000). Nevertheless, despite this heterogeneity in trajectories, both cluster solutions have an ASW-value of 0.46 and 0.64 , respectively, clearly identifying eight types of trajectory. This prevents the interpretation of complete de-standardization of the life course, and rather suggests the emergence of a limited number of alternative trajectories. It is also possible that post-divorce partner trajectories may once more become more standardized in the future. The men and women in the present study divorced in a period in which post-divorce unmarried cohabitation was gradually replacing remarriage as the standard living arrangement for higher order unions in Flanders (Pasteels, Lodewijckx, and Mortelmans 2013). At the end of this transition period, post-divorce partner trajectories may become more similar than during the transition period. For example, there might be a further decrease in the size of the clusters Unmarried cohabitation $\rightarrow$ remarriage and Fast remarriage, and an increase in the size of the clusters Fast unmarried cohabitation and Single $\rightarrow$ unmarried cohabitation. With regard to post-divorce parenthood trajectories, population 
figures indicate that single parents increasingly meet potential partners who also have children from a previous relationship, and that unions are frequently dissolved before men and women have realized their fertility aspirations. We might expect that these two trends will lead to a growing proportion of men and women in post-divorce family trajectories that involve at least one parenthood transition, or the two consecutive transitions of becoming a step-parent and experiencing an (additional or first) birth within a relatively short period of time.

Finally, next to the heterogeneity in partner and parenthood trajectories, it is important to stress that a large proportion of men and women remain single or outside a union and make no parenthood transition at all within the first seven years following divorce. In terms of relative frequency, we could even claim that this is the standard post-divorce family trajectory. Future studies could bring more insight into the demographic (e.g., age) and socio-economic (e.g., educational level) characteristics of men and women in this cluster, and into the demographic and socio-economic profile of persons in the other family trajectories. Another important question for future research is the extent to which the results are extendable to other western countries. As there are substantive differences between countries in the rate and characteristics of LATrelationships, unmarried cohabitation, marriage, and childbearing, we might expect considerable cross-national variation in the prevalence of specific post-divorce family trajectories. 


\section{References}

Abbott, A. and Forrest, J. (1986). Optimal matching methods for historical sequences. Journal of Interdisciplinary History 16: 471-494. doi:10.2307/204500.

Bastaits, K., Van Peer, C., Alofs, E., Pasteels, I., and Mortelmans, D. (2011). Hoe verloopt een echtscheiding in Vlaanderen? In: Mortelmans, D., Pasteels, I., Bracke, B., Matthijs, K., Van Bavel, J., and Van Peer, C. (eds.). Scheiding in Vlaanderen. Leuven: Acco: 85-112.

Beaujouan, E. (2012). Repartnering in France: The role of gender, age and past fertility. Advances in Life Course Research 17: 69-80. doi:10.1016/j.alcr.2012.03.001.

Buber, I. and Prskawetz, A. (2000). Fertility in second unions in Austria: Findings from the Austrian FFS. Demographic Research 3(2). doi:10.4054/DemRes.2000.3.2.

Corijn, M. (2013). Veranderingen in de burgerlijke staat doorheen de levensloop. In: Corijn, M. and Van Peer, C. (eds.). Gezinstransities in Vlaanderen. Brussels: Studiedienst van de Vlaamse Regering, SVR-studie: 21-36.

Elzinga, C.H. (2007). Sequence analysis: Metric representations of categorical time series. Amsterdam: Vrije Universiteit Amsterdam, Dept of Social Science Research Methods.

Gabadinho, A., Ritschard, G., Studer, M., and Müller, N. (2011a). Mining sequence data in $R$ with the TraMineR package: A user's guide (for version 1.8). Geneva: University of Geneva, Department of Econometrics and Laboratory of Demography.

Gabadinho, A., Ritschard, G., Müller, N., and Studer, M. (2011b). Analyzing and Visualizing State Sequences in R with TraMineR. Journal of Statistical Software 40(4): $1-37$.

Green, L. (2010). Understanding the life course. Sociological and psychological perspectives. Cambridge: Polity Press.

Jefferies, J., Berrington, A., and Diamond, I. (2000). Childbearing following marital dissolution in Britain. European Journal of Population 16(3): 193-210. doi:10.1023/A:1026529300659.

Mortelmans, D., Pasteels, I., Van Bavel, J., Bracke, P., Matthijs, K., and Van Peer, C. (2011). Divorce in Flanders. Data collection and code book. http://www.divorceinflanders.be. 
Pasteels, I., Corijn, M., and Mortelmans, D. (2012). Een nieuwe partner na een echtscheiding? Opleidingsverschillen bij mannen en vrouwen in Vlaanderen. Tijdschrift voor Sociologie 33(3-4): 331-352.

Pasteels, I., Lodewijckx, E., and Mortelmans, D. (2013). Gezinstransities in de levensloop van mannen en vrouwen. In: Corijn, M. and Van Peer, C. (eds.). Gezinstransities in Vlaanderen. Brussels: Studiedienst van de Vlaamse Regering: 37-72.

Shanahan, M.J. (2000). Pathways to adulthood: Variability and mechanisms in life course perspective. Annual Review of Sociology 26: 667-692. doi:10.1146/ann urev.soc.26.1.667.

Studer, M. (2012). Etude des inégalitées de genre en début de carrière académique à l'aide de méthodes innovatrices d'analyse de données séquentielles, Chapitre: Le manuel de la librairie WeightedCluster: Un guide pratique pour la création de typologies de trajectoires en sciences sociales avec $\mathrm{R}$ [PhD thesis]. Geneva: University of Geneva, Faculty of Social and Economic Sciences.

Wu, Z. and Schimmele, C.M. (2005). Repartnering after first union disruption. Journal of Marriage and Family 67(1): 27-36. doi:10.1111/j.0022-2445.2005.00003.x. 